\title{
Modeling and Control of Fuel Cell/Supercapacitor Hybrid Source Based on Energetic Macroscopic Representation
}

\author{
Mohamed Haidoury*, Hatim Jbari**, and Mohammed Rachidi*** \\ Modeling, Information Processing and Control Systems (MPICS), National High School of Arts and Crafts of Meknes (ENSAM- \\ Meknes), Moulay Ismail University, Meknes, Morocco
}

\begin{abstract}
In this paper, we present a dynamic simulator that uses a proton exchange membrane fuel cell (PEMFC). This source, is used as a primary source with a supercapacitor (SC) considered as a secondary source. This simulator integrates a PEMFC's dynamic model, validated on the Bahia bench and a semiempirical model of SC. The developed model is implemented using the macroscopic energetic representation tool (EMR). The energy management system (EMS) is based on rule-based power management, where a low-pass filter splits the power among sources (PEMFC and SCs) using a cut-off frequency of $0.2 \mathrm{~Hz}$, and a controller block that regulates the bus voltage deduced by the EMR's inversionbased control approach.
\end{abstract}

\section{Introduction}

The world consumption of fossil fuels has been growing continuously for more than half a century. Fossil fuels are becoming scarcer by the day. This scarcity is accompanied today by a feeling of duty towards nature and the environment. Thus, science is obliged to remedy, or at least minimize, the harmful effects of the consumption of fossil fuels and to be able to partially replace them. In this context, hybrid vehicles with a fuel cell (FC) are an essential solution for the future. These vehicles are powered by a FC assisted by a secondary energy source (SES). This secondary energy source consists of batteries and/or supercapacitors. The optimal energy distribution between the FC and the SSE is obtained thanks to global optimization algorithms that allow to minimize the hydrogen consumption by FC and to extend its lifetime. Therefore, in order to develop hybrid system simulators, it is necessary to couple dynamic models of the sources and the power converters.

In the literature, some studies of Modeling and control PAC use the EMR approach [1-4]. In these works, the proposed PEMFC models predict the electrical, fluidic and / or thermal dynamics, they introduce control loops based on the EMR inverse control. Other dynamic Models has been proposed, including equivalent electrical circuit [5].

For supercapacitors, a simplified model is deduced from the equivalent circuit proposed in $[1,6]$.
Regarding energy management strategies at the hybrid vehicle level, current studies focus on the architecture for connecting different sources to the power converters and the load [7,8], as well as the control strategies used for EMS in hybrid generators. Such as filtering of sources $[1,7,9]$. Considering the same control objective, research works $[10,11]$ have analysed the real-time energy management strategies for hybrid battery-supercapacitor sources in electric traction applications.

The main objective of this paper is, firstly, to provide dynamic models of the hybrid source including FC and SSE such SCs. Secondly, a hybrid simulator allowing power distribution control among FC and the SSE. Rule-based algorithms and optimization were developed. The performance of the algorithms was evaluated on a ECE driving profile.

\section{Materials and methods}

The dynamic model of the heat pump has been validated with the BAHIA test bench. This bench is equipped with a PEMFC device, with a maximum power of $1.2 \mathrm{~kW}$. This bench allows a variety of experiments [12].

\footnotetext{
* Corresponding author: haidoury.mohamed@gmail.com

** Corresponding author: hatim.jbari@gmail.com

*** Corresponding author: morachidi@yahoo.fr
} 


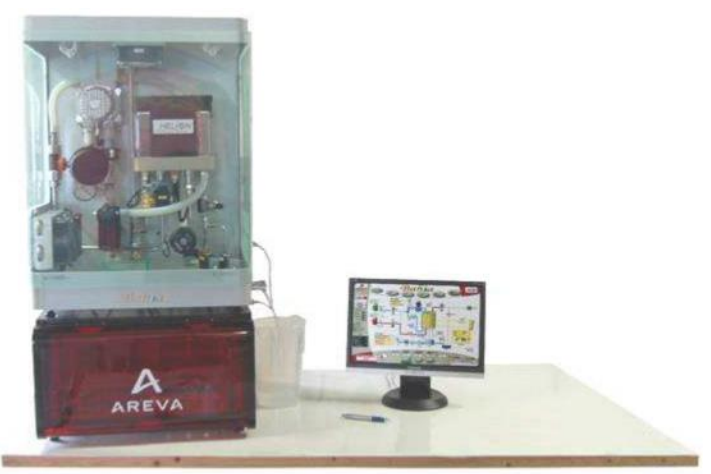

Fig. 1. The Bahia bench.

The supercapacitor model has been validated with the Maxwell module : MOD0500 P016 B01, this module is characterized with a nominal voltage of $37.8 \mathrm{~V}$, a capacity of $305 \mathrm{~F}$, and contains 14 SCs cells connected in series [13].

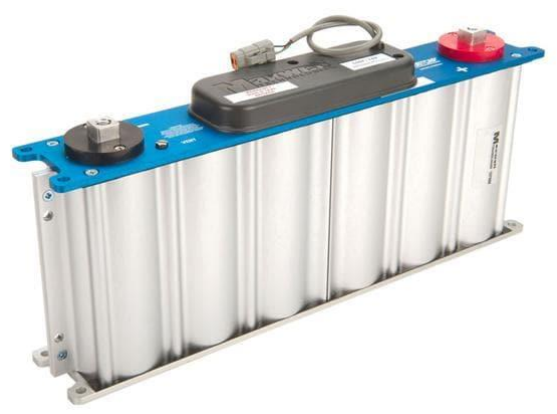

Fig. 2. The Maxwell module MOD0500 P016 B01.

\section{Hybrid simulator based on the FC}

\subsection{PEMFC Modeling}

The FC system is a device that directly converts chemical energy into electrical energy. The operating principle of a PEMFC is described by a chemical redox reaction. This reaction makes Hydrogen (Reducing Fuel) react with Oxygen (Oxidizing Fuel) to produce water, heat and electricity.

The PEMFC model is developed using the EMR based on the causal graph, is obtained from the set of multiphysics equations (1), (2), (3) and (4) below:

- Fluidic field:

$P_{x}=P s c_{x}+R d e_{x} \cdot q_{x}$

$\frac{d P s c_{x}}{d t}=\frac{1}{C d_{x}}\left(q_{x}-q c_{x}-q_{x-o u t}\right)$

$q_{x-\text { out }}=\left(P s c_{x}-P s_{x}\right) \cdot R d s_{x}$

- Physico-chemical field:

$E_{n}=E_{0}+\Delta E$

$E_{0}=1,4648-4,5 T_{f c}+1,0256 \cdot 10^{-8} T_{f c}{ }^{2}+9,52 \cdot 10^{-13} T_{f c}{ }^{3}$

$\Delta E=\frac{R \cdot T_{f c}}{N_{e} \cdot F} \ln \left(\frac{P s c_{H 2}}{P_{0}}\right)+\frac{-5,989.10^{-5} T_{f c}}{2 \cdot N_{e} \cdot F} \ln \left(\frac{P s c_{O 2}}{P_{0}}\right)$

$\Delta V=\frac{R \cdot T_{f c}}{N_{e} \cdot F \cdot A} \ln \left(\frac{I_{f c}+I_{n}}{I_{0}}\right)+\frac{R \cdot T_{f c} \cdot B_{H 2} \cdot B_{O 2}}{F \cdot A} \ln \left(1-\frac{I_{f c}}{I_{l}}\right)+R_{m} \cdot I_{f c}$
- Thermal field:

$\Delta S_{f c}=\Delta S_{q 0}+\Delta S_{q n}+\Delta S_{q}$
$\Delta S_{q 0}=-98,2892+3,9582 \cdot 10^{-3} \cdot T_{f c}+5,5112 \cdot 10^{-7} \cdot T_{f c}{ }^{2}$
$\Delta S_{q n}=\frac{\Delta E . I f c}{T_{f c}} \quad-11,5575 \cdot \ln \left(T_{f c}\right)$
$\Delta S_{q}=\frac{\Delta V . I+\left(R_{m}+R t\right) I_{f c}{ }^{2}}{T_{f c}}$

- Electrical field:

Rt. C. $\frac{d V_{c}}{d t}+V_{c}=R t . I_{f c}$

$V_{f c}=N_{c} \cdot\left(V_{M}+V_{c}\right)$

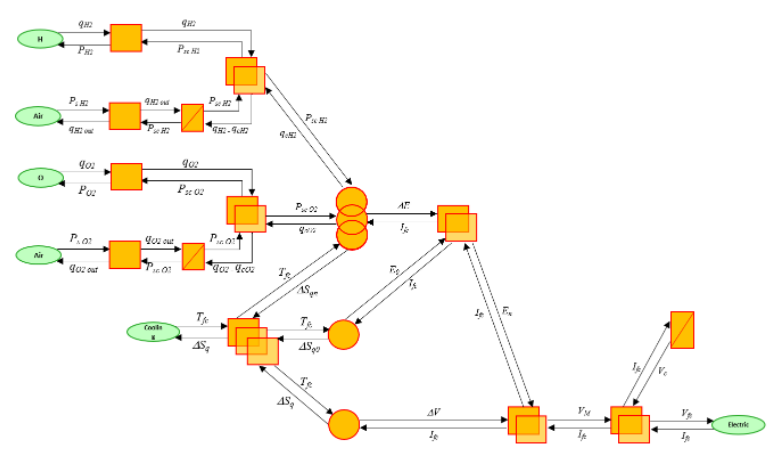

Fig. 3. EMR of the PEMFC.

\subsection{Supercapacitor Modeling}

The supercapacitor is an electrochemical capacitor with a high energy density. It allows the storage of static electrical energy. It does not require any chemical reaction. In electric traction applications supercapacitors are used in transient regimes. The simulation model used the performance evaluation of SC pack, is given by (5).

$V_{S C}=R_{i} I_{S C}+\frac{1}{C_{0}+C_{i 1} V_{S C}} \int I_{S C} d t$

The developed SC's EMR is shown in Figure 4 below. The model parameters are $\mathrm{R}_{\mathrm{ESR}}=34 \mathrm{~m} \Omega, \mathrm{C}_{0}=$ $305 \mathrm{~F}$ and $\mathrm{C}_{\mathrm{i} 1}=10.5075 \mathrm{~F} / \mathrm{V}$.

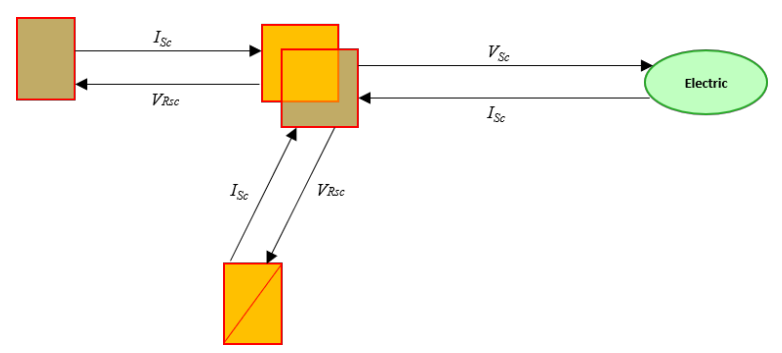

Fig. 4. EMR of the supercapacitor.

\subsection{DC-DC converter Modeling}

To integrate the hybrid sources with the load, a twoconverters architecture is adopted, this configuration is described in Figure $5[1,7]$. 


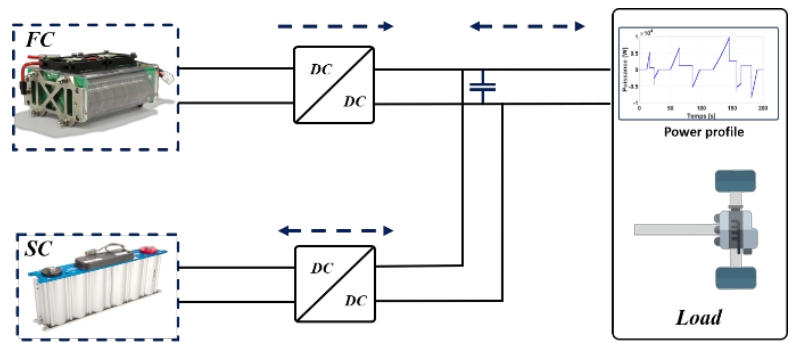

Fig. 5. Schematic diagram of the two-converter structure.

The FC is coupled with a boost elevator DC-DC converter, while SC is coupled with a bidirectional DCDC converter. Both converters are modeled by ideal switching devices, represented by equations (6) (7) (8) (9) (10) and (11). The D parameter represents the duty cycle. A coupling capacitor is used to connect the FC, $\mathrm{SC}$ and load to a DC bus. The model system is developed under EMR approach, which is shown in Figure 6 below:

$$
\begin{aligned}
& V_{I G B T_{f c}}=D_{f c} V_{b u s} \text { and } I_{I G B T_{f c}}=D_{f c} I_{b u s} \\
& V_{I G B T_{s c}}=D_{s c} V_{b u s} \text { and } I_{I G B T_{s c}}=D_{s c} I_{s c} \\
& I_{f c}=\frac{1}{L_{f c}} \int\left(V_{f c}-V_{I G B T_{f c}}\right) d t \\
& I_{s c}=\frac{1}{L_{s c}} \int\left(V_{s c}-V_{I G B T_{s c}}\right) d t \\
& V_{\text {bus }}=\frac{1}{c_{\text {coupling }}} \int\left(I_{I G B T_{f c}}-I_{\text {coupling }}\right) d t \\
& I_{\text {coupling }}=I_{\text {bus }}-I_{I G B T_{s c}}
\end{aligned}
$$

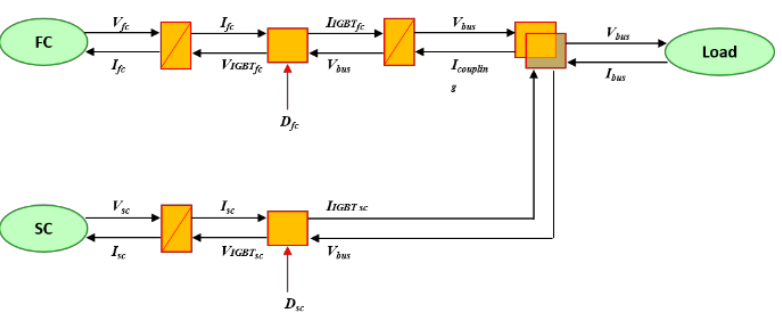

Fig. 6. EMR of the power conversion unit.

\subsection{Hybrid system control}

The control of the hybrid system is done in two stages, a first stage for local control of the sources which allows internal current control and external voltage regulation. The second stage concerns global control of the power converters, using the EMR inversion-based control. Figure 7 represents the control of the hybrid simulator; the blue parallelograms symbolize the control elements.

\subsection{Power management strategy}

To ensure the power split among the primary source (FC) and the secondary source (SC), the frequency decomposition is adopted, using a first order low-pass filter, shown in Figure 8. The load power demand is represented in the frequency domain using the Fast Fourier Transform (FFT) principle. Thus, the power signal is decomposed into a high frequency component taken by SC and low frequency used for FC, the cut-off frequency depends on FC's capacities, which is characterised by a slow dynamic response. In addition, a cut-off frequency was determined by voltage-current measurements in [7]. The chosen cut-off frequency of $0.05 \mathrm{~Hz}$ enables system to avoid abrupt changes in the FC pack. Moreover, the Bahia bench cut-off frequency is $0.2 \mathrm{~Hz}$ [1].

In this study, the power distribution is mainly evaluated for a cut-off frequency of $0.2 \mathrm{~Hz}$, the FC is considered as the main source that provides the steadystate power, while the SC is mainly used to provide power in the transient regime.
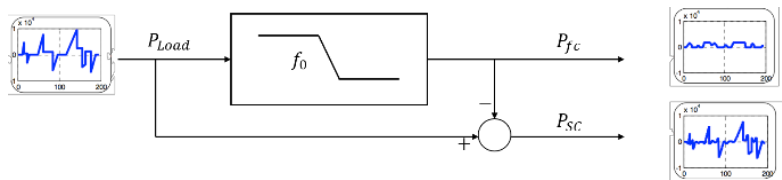

Fig. 8. Power split between the sources.

\section{Results and discussions}

The EMR library, developed at the University of Lille, France [14], is used to build simulation model under Matlab/ Simulink. The hybrid simulator, is developed with its local control is presented in Figure 9 below:

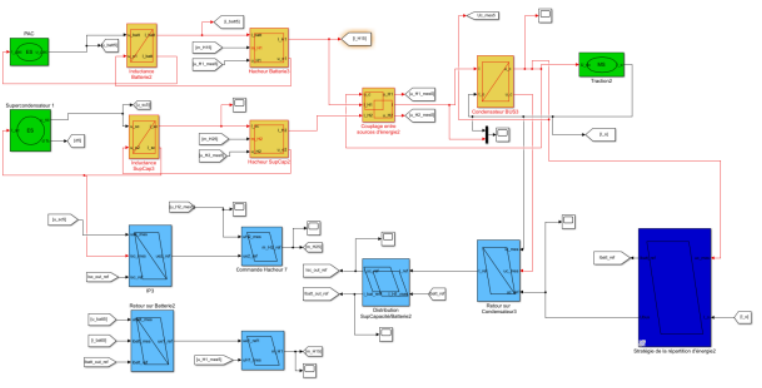

Fig. 9. Simulation model used in Matlab/ Simulink.

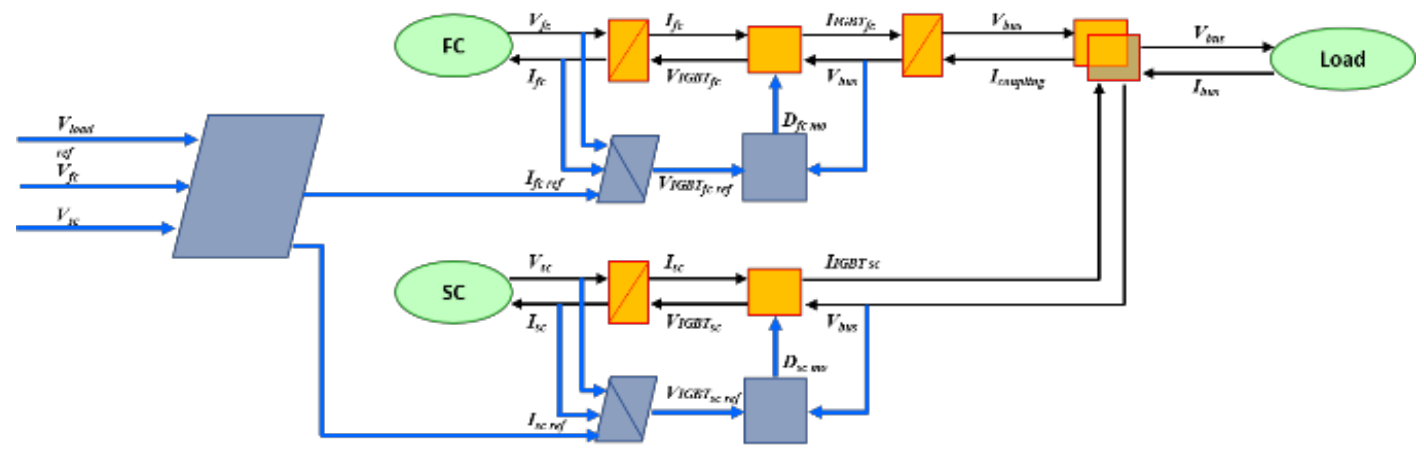

Fig. 7. EMR of the hybrid powertrain. 
The evaluation of the developed hybrid simulator performances, was conducted under the power profile calculated from the new European driving cycle (NEDC) ECE-15, and the mechanical dynamic parameters of the vehicle described in equation (12) [7]. The profile is scaled to $1 \mathrm{~kW}$ to fit the maximum power of the Bahia bench.

$P_{m}=V \cdot\left[C_{r} \cdot M \cdot g \cdot \cos \alpha+M \cdot g \cdot \sin \alpha+M \cdot \frac{d V}{d t}+\frac{1}{2} \rho \cdot S \cdot C_{x} \cdot V^{2}\right]$

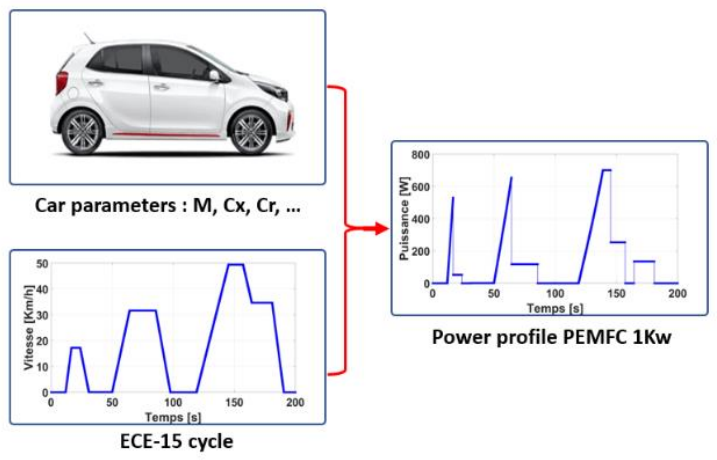

Fig. 10. Power profile used in experimentations.

The simulation results under ECE-15, show that the hybridization based on FC and SC, allow the proposed system to assure the power request by powertrain, in order to accomplish the driving cycle. In the other hand, this operation was executed without compromising the DC-BUS voltage Figure 11, which should be stable, in spite of power request variations. The bus voltage is regulated using a PI at $36 \mathrm{~V}$ despite sudden changes in the power load $300 \mathrm{~W}$. The converters assure power supply and absorption, during periods of delivery and recovery of energy.

Figure 11 shows SC takes in charge the power demand in the transient regimes, like acceleration, and regenerative brakes phases, with negative power generated by powertrain. The study-state phases are taken by FC with high power supply.

Moreover, the SoCsc is maintained in the same range $[50 \%, 100 \%]$, which ensure SC's energetic efficiency, the SC helps to recover energy, the SOC of the $\mathrm{SC}$, is maintained between 85 and $97 \%$ throughout the simulation. The results show that SOCsc remains within safe operating limits, leading to higher use of SC in transient regimes.

The energy management based on filtering using a low pass filter with a cutoff frequency of $0.2 \mathrm{~Hz}$, demonstrates that the objectives of the strategy have been achieved. As the total power required to satisfy the traction of the vehicle for the driving cycle is delivered smoothly, the fuel cell provides the bulk of the power Figure 12, showing maximum utilization of the fuel cell, compared with SC contribution.
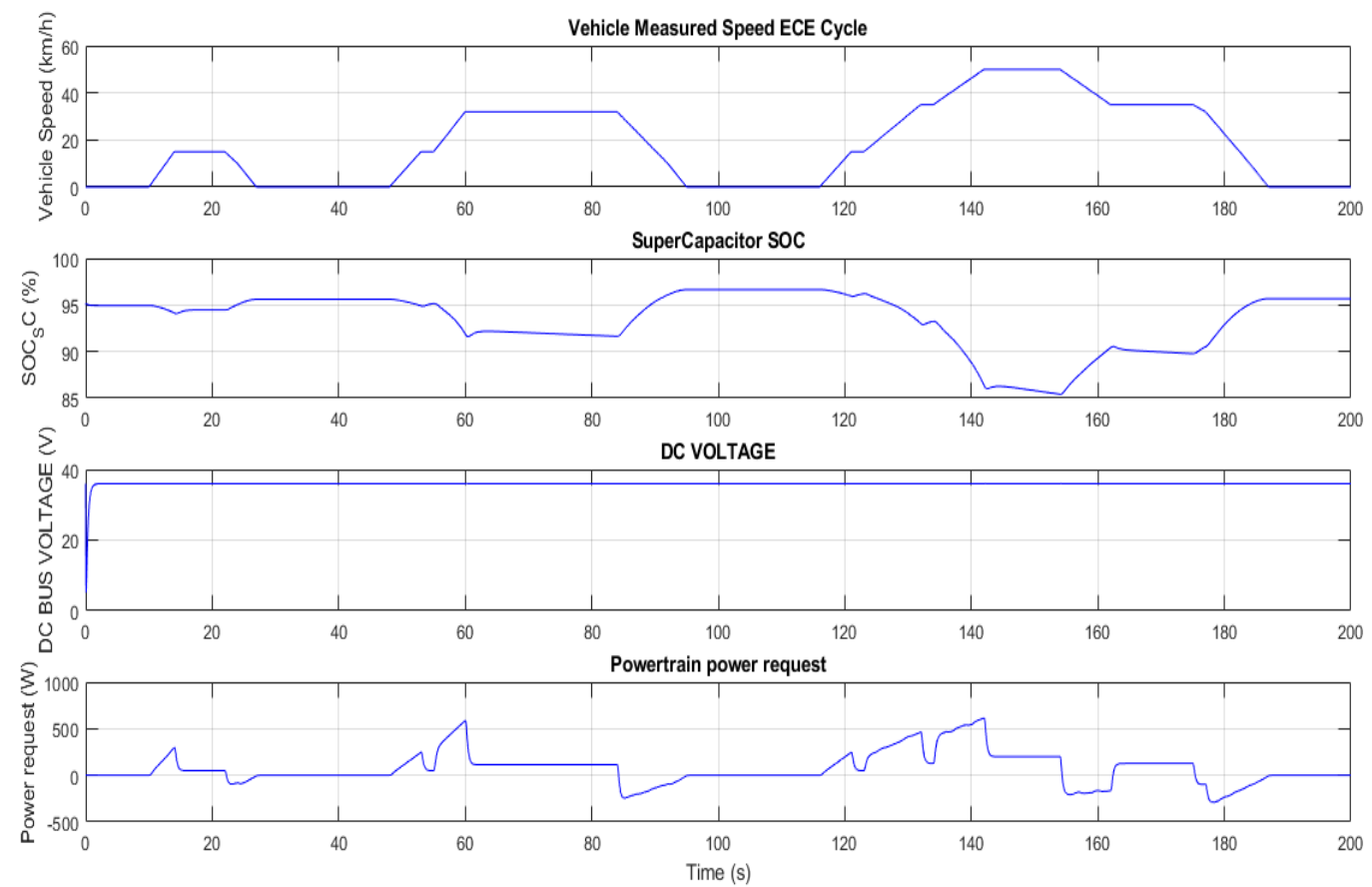

Fig. 11. Simulation results under ECE-15. 


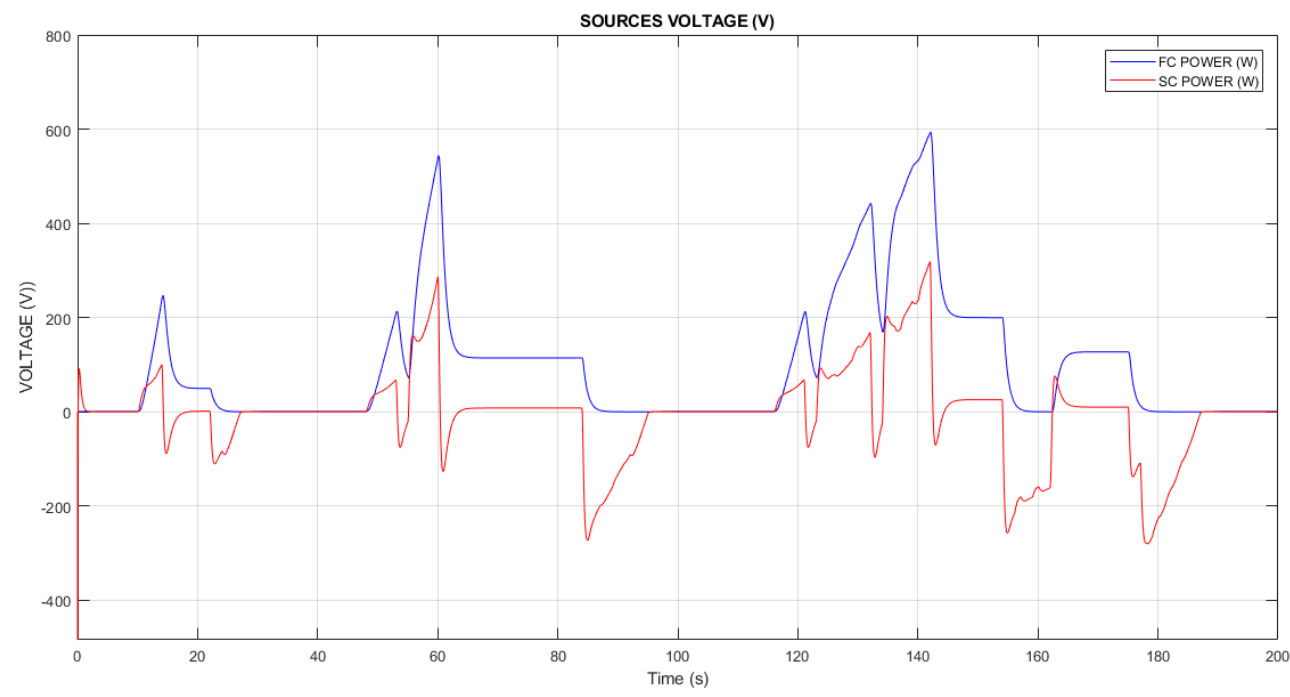

Fig. 12. Sources powers.

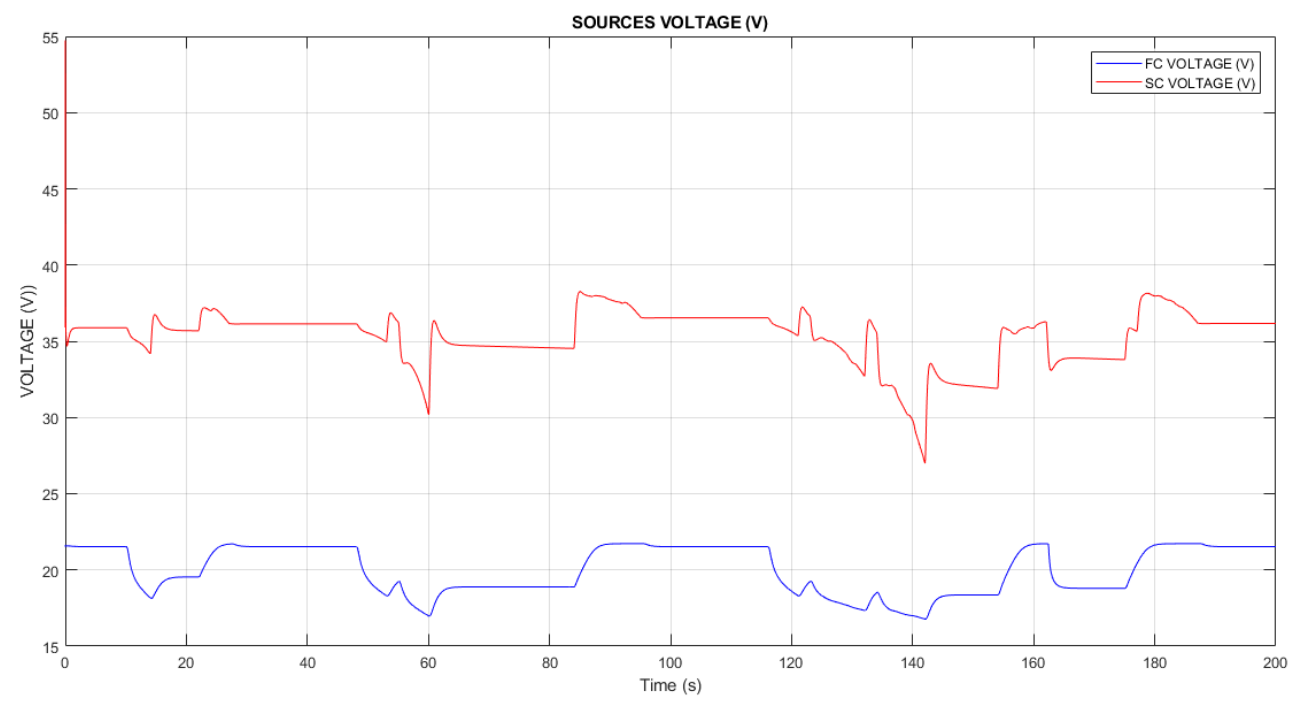

Fig. 13. Sources voltages.

Figure 13 shows that, the sources voltages respect the maximum voltage, specified respectively in the FC's performances $(22 \mathrm{~V})$, and SC's (40V).

\section{Conclusion}

The hybrid simulator proposed in this work, was developed using a dynamic model of the FC, considered as the primary source and a SC used as the secondary source. The energy storage system is coupled with twoconverter architecture. The energy distribution between different sources is assured by a first order low-pass filter, with a cut-off frequency of $0.2 \mathrm{~Hz}$.

This work, represents a first step to develop a simulation model, which can be upgraded in future works, especially for an efficient power split among FC and SC, using an advanced EMSs based on deterministic or optimisation approach.

\section{APPENDIX: Synoptic of Energetic Macroscopic Representation (EMR)}

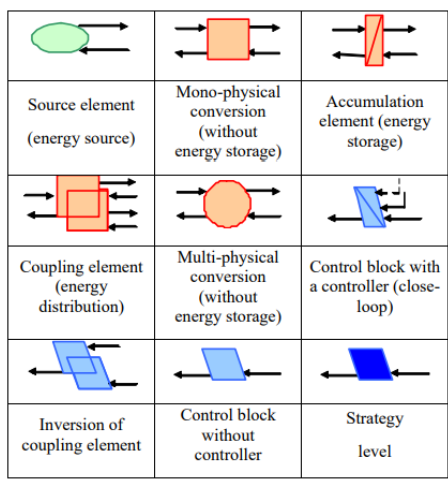


Table. 1. Nomenclature.

\begin{tabular}{|c|c|}
\hline $\mathrm{x}$ & $\mathrm{H}_{2}$ gas at the Anode or $\mathrm{O}_{2}$ gas at the Cathode \\
\hline$P_{x}$ & Partial pressure at the inlet gas of the electrode $\times\left(\mathrm{N} / \mathrm{m}^{2}\right)$ \\
\hline Psc $x$ & Partial pressure of gas $x$ at the electrode catalytic $\left(\mathrm{N} / \mathrm{m}^{2}\right)$ \\
\hline Ps $x$ & $\begin{array}{l}\text { Partial pressure of gas } x \text { at the outlet of the electrode } \\
\left(\mathrm{N} / \mathrm{m}^{2}\right)\end{array}$ \\
\hline$q_{x}$ & Gas flow $x$ at the electrode inlet $\left(\mathrm{m}^{3} / \mathrm{s}\right)$ \\
\hline$q_{c x}$ & Gas flow $x$ consumed by the reaction $\left(\mathrm{m}^{3} / \mathrm{s}\right)$ \\
\hline$q_{\text {x_out }}$ & Gas flow $x$ at the electrode outlet $\left(\mathrm{m}^{3} / \mathrm{s}\right)$ \\
\hline $\operatorname{Rde}_{x}$ & $\begin{array}{l}\text { Fluid resistance at the inlet of the gas electrode } x \\
\left(\mathrm{~N} . \mathrm{s} / \mathrm{m}^{5}\right)\end{array}$ \\
\hline $\operatorname{Rds} \times$ & $\begin{array}{l}\text { Fluid resistance at the outlet of the gas electrode } x \\
\left(\mathrm{~N} . \mathrm{s} / \mathrm{m}^{5}\right)\end{array}$ \\
\hline$C d_{x}$ & Fluidic capacity of the gas electrode $\times\left(\mathrm{m}^{5} / \mathrm{N}\right)$ \\
\hline$E_{n}$ & Nernst potential (V) \\
\hline$E_{0}$ & Thermodynamic potential (V) \\
\hline$\Delta \mathrm{E}$ & Potential variation $(\mathrm{V})$ \\
\hline$\Delta V$ & Voltage drop (V) \\
\hline$V_{M}$ & Le potentiel de cellule sans l'impédance d'électrode (V) \\
\hline$V_{c}$ & $\begin{array}{l}\text { Le Potentiel de cellule aux bornes de l'impédance } \\
\text { d'électrode (V) }\end{array}$ \\
\hline $\mathrm{V}_{\mathrm{fc}}$ & Fuel cell voltage $(\mathrm{V})$ \\
\hline$\Delta S$ & Molar entropy (J./K/mol) \\
\hline$\Delta \mathrm{S}$ 。 & Molar entropy variation $(\mathrm{J} . / \mathrm{K} / \mathrm{mol})$ \\
\hline$\Delta \dot{\mathrm{S}}_{\mathrm{N}}$ & Entropy flow $(\mathrm{W} / \mathrm{K})$ \\
\hline$\Delta \dot{\mathrm{S}}$ an & Entropy flow losses (W/K) \\
\hline$\Delta \dot{\mathrm{S}}_{\mathrm{q}}$ & Entropy flux released by heat (W/K) \\
\hline c & Heat capacity \\
\hline$T_{\mathrm{fc}}$ & Operating temperature $(\mathrm{K})$ \\
\hline$I_{\mathrm{fc}}$ & Operating current (A) \\
\hline I, & Limiting current $(A)$ \\
\hline$I_{0}$ & Exchange current $(A)$ \\
\hline $\operatorname{In}$ & Internal current (A) \\
\hline $\mathrm{R}_{\mathrm{t}}$ & Charge Transfer Resistance $(\Omega)$ \\
\hline$R_{\mathrm{m}}$ & Ohmic resistance $(\Omega)$ \\
\hline$B_{x}$ & Gas stoichiometry coefficient $x$ \\
\hline $\mathrm{R}$ & Perfect gas constant $(\mathrm{R}=8.3144621 \mathrm{~J} . \mathrm{mol} / \mathrm{K})$ \\
\hline$P_{0}$ & Atmospheric pressure $\left(\mathrm{P}_{0}=101325 \mathrm{~Pa}\right)$ \\
\hline$T_{0}$ & Standard temperature $\left(T_{0}=298.15 \mathrm{~K}\right)$ \\
\hline $\mathrm{Ne}_{\mathrm{e}}$ & Number of electrons exchanged \\
\hline $\mathrm{N}_{\mathrm{c}}$ & Number of stack \\
\hline $\mathrm{F}$ & Faraday constant $(\mathrm{F}=96485 \mathrm{C} / \mathrm{mol})$ \\
\hline A & Charge transfer coefficient $(0<A<1)$ \\
\hline Csc & SC Capacitance (F) \\
\hline RISR & Equivalent series resistance $(\Omega)$ \\
\hline$V_{\text {bus }}$ & DC bus voltage $(\mathrm{V})$ \\
\hline lbus & DC BUS Current (A) \\
\hline SOCsc & SC State Of Charge (\%) \\
\hline
\end{tabular}

\section{References}

[1] G. Lopez Lopez, R. Schacht Rodriguez, V. M. Alvarado, J. F. Gomez-Aguilar, J. E. Mota, and C. Sandoval, "Hybrid PEMFC-supercapacitor system: Modeling and energy management in energetic macroscopic representation," Appl. Energy, vol. 205, pp. 1478-1494, Nov. 2017, doi: 10.1016/j.apenergy.2017.08.063.

[2] L. Boulon, K. Agbossou, D. Hissel, P. Sicard, A. Bouscayrol, and M.-C. Péra, "A macroscopic PEM fuel cell model including water phenomena for vehicle simulation," Renew. Energy, vol. 46, pp. 81-91, Oct. 2012, doi: 10.1016/j.renene.2012.03.009.

[3] L. Boulon, D. Hissel, A. Bouscayrol, and M.-C. Pera, "From Modeling to Control of a PEM Fuel Cell Using Energetic Macroscopic Representation," IEEE Trans. Ind. Electron., vol.
57, no. 6, pp. 1882-1891, Jun. 2010, doi: 10.1109/TIE.2009.2026760.

[4] K. S. Agbli, D. Hissel, M.-C. Péra, and I. Doumbia, "EMR modelling of a hydrogen-based electrical energy storage," Eur. Phys. J. Appl. Phys., vol. 54, no. 2, p. 23404, May 2011, doi: 10.1051/epjap/2010100272.

[5] S. Lazarou, E. Pyrgioti, and A. T. Alexandridis, "A simple electric circuit model for proton exchange membrane fuel cells," J. Power Sources, vol. 190, no. 2, pp. 380-386, May 2009, doi: 10.1016/j.jpowsour.2009.01.065.

[6] M. Trabelsi, J.-F. Charpentier, F. Scuiller, C. Franquet, and E. Nicolas, "Energetic Macroscopic Representation and Inversion-Based Control of a Grid-Connected MCT Power Generation System with Super-Capacitor Based Energy Storage Unit in Ushant Island," in 2019 Offshore Energy and Storage Summit (OSES), BREST, France, Jul. 2019, pp. 1-9. doi: 10.1109/OSES.2019.8867324.

[7] T. AZIB, “Contribution à l'Etude d'Electrogénérateurs à Pile à Combustible," UNIVERSITE PARIS-SUD XI Faculté des Sciences d'Orsay, Ecole Doctorale « Sciences et Technologies de l'Information des Télécommunications et des Systèmes », 2010.

[8] M. Yue, "Contribution of developing a prognostics-based energy management strategy for fuel cell hybrid system - application to a fuel cell/battery hybrid electric vehicle," p. 186.

[9] C. Sandoval, V. M. Alvarado, J.-C. Carmona, G. Lopez Lopez, and J. F. Gomez-Aguilar, "Energy management control strategy to improve the FC/SC dynamic behavior on hybrid electric vehicles: A frequency based distribution," Renew. Energy, vol. 105, pp. 407-418, May 2017, doi: 10.1016/j.renene.2016.12.029.

[10] Y. Wang, Z. Sun, and Z. Chen, "Development of energy management system based on a rule-based power distribution strategy for hybrid power sources," Energy, vol. 175, pp. 1055-1066, May 2019, doi: 10.1016/j.energy.2019.03.155.

[11] T. Yuan, X. Dong, X. Chen, W. Cao, J. Hu, and C. Liu, "Energetic macroscopic representation control method for a hybrid-source energy system including wind, hydrogen, and fuel cell," $J$. Renew. Sustain. Energy, vol. 10, no. 4, p. 043308, Jul. 2018, doi: 10.1063/1.5038091.

[12] HELION, MANUEL D'UTILISATION ET D'INSTALLATION BANC DIDACTIQUE BAHIA Type : Bahia V2.1-A1, V2.1-A1. 2009.

[13] Maxwell Technologies, Maxwell Technologies DATASHEET BMOD0500 P016 16V MODULES, vol. 1009363.10. [Online]. Available: maxwell.com

[14] "EMRwebsite - Accueil." http://emr.univ-lille1.fr/ (accessed Jan. 29, 2021). 